\title{
CONRAD'S PARTIAL ORDER ON P.Q.-BAER *-RINGS
}

\author{
ANIL KHAIRnAR \\ Department of Mathematics \\ Abasaheb Garware College, Pune-411004, India \\ e-mail: anil.khairnar@mesagc.org \\ anil_maths2004@yahoo.com \\ AND \\ B.N. WAPHARE \\ Center for Advanced Studies in Mathematics \\ Department of Mathematics \\ Savitribai Phule Pune University, Pune-41100\%, India \\ e-mail: bnwaph@math.unipune.ac.in \\ waphare@yahoo.com
}

\begin{abstract}
We prove that a p.q.-Baer *-ring forms a pseudo lattice with Conrad's partial order and also characterize p.q.-Baer $*$-rings which are lattices. The initial segments of a p.q.-Baer *-ring with the Conrad's partial order are shown to be an orthomodular posets.
\end{abstract}

Keywords: Conrad's partial order, p.q.-Baer *-ring, central cover, orthomodular set.

2010 Mathematics Subject Classification: Primary 16W10; Secondary 06A06, 47L30.

\section{REFERENCES}

[1] A. Abian, Direct product decomposition of commutative semisimple rings, Proc. Amer. Math. Soc. 24 (1970) 502-507.

doi:10.2307/2037396

[2] J.K. Baksalary and S.K. Mitra, Left-star and right-star partial ordering, Linear Algebra Appl. 149 (1991) 73-89.

doi:10.1016/0024-3795(91)90326-R 
[3] S.K. Berberian, Baer*-Rings, Grundlehren Math. Wiss. Band 195. Vol. 296 (Berlin, Springer, 1972).

doi:10.1007/978-3-642-15071-5

[4] G.F. Birkenmeier, J.K. Park and S.T. Rizvi, Principally quasi-Baer rings hulls, Advances in Ring Theory Trends in Mathematics, 47-61 (Birkhäuser Basel, 2010). doi:10.1007/978-3-0346-0286-0 \_4

[5] G.F. Birkenmeier, J.K. Park and S.R. Tariq, Extensions of Rings and Modules (New York, Birkhäuser, 2013). doi:10.1007/978-0-387-92716-9

[6] W.D. Burgess and R. Raphael, On Conrad's partial order relation on semiprime rings and on semigroups, Semigroup Forum 16 (1978) 133-140. http://eudml.org/doc/134282

[7] J. Cīrulis, Quasi-orthomodular posets and weak BCK-algebras, Order 31 (2014) 403-419. doi:10.1007/s11083-013-9309-1

[8] P.F. Conrad, The hulls of semiprime rings, Austral. Math. Soc. 12 (1975) 311-314. doi:10.1017/S0004972700023911

[9] G. Dolinar and J. Marovt, Star partial order on $B(H)$, Linear Algebra Appl. 434 (2011) 319-326. doi:10.1016/j.laa.2010.08.023

[10] G. Dolinar, B. Kuzma and J. Marovt, A note on partial orders of Hartwig, Mitsch, and $\breve{S}$ emrl, Appl. Math. and Comp. 270 (2015) 711-713. doi:10.1016/j.amc.2015.08.066

[11] M.P. Drazin, Natural structure on semigroup with involution, Bull. Amer. Math. Soc. 84 (1978) 139-141. https://projecteuclid.org/euclid.bams/1183540393

[12] R.E. Hartwig, How to partially order regular elements, Math. Japon. 25 (1980) 1-13.

[13] R.E. Hartwig, Pseudo lattice properties of the star-orthogonal partial ordering for star-regular rings., Proc. Amer. Math. Soc. 77 (1979) 299-303. doi: $10.2307 / 2042174$

[14] C.Y. Hong, N.K. Kim, T.K. Kwak, Ore extension of Baer and PP rings, J. Pure Appl. Algebra 151 (2000) 215-226. doi:10.1016/S0022-4049(99)00020-1

[15] M.F. Janowitz, On the *-order for Rickart *-rings, Algebra Universalis 16 (1983) 360-369. doi:10.1007/BF01191791

[16] I. Kaplansky, Rings of Operators (W.A. Benjamin, Inc., New York-Amsterdam, 1968).

[17] A. Khairnar and B.N. Waphare, Unitification of weakly p.q.-Baer *-rings, Southeast Asian Bull. Math. (to appear).

arXiv:1612.01681 
[18] A. Khairnar and B.N. Waphare, Order properties of generalized projections, Linear Multilinear Algebra 65 (2017) 1446-1461. doi:10.1080/03081087.2016.1242554

[19] A. Khairnar and B.N. Waphare, Generalized Projections in $\mathbb{Z}_{n}$, AKCE Int. J. Graphs Comb. doi:10.1016/j.akcej.2018.01.010

[20] A. Khairnar and B.N. Waphare, A Sheaf Representation of Principally Quasi-Baer *-Rings, Algebr. Represent. Theory. https://doi.org/10.1007/s10468-017-9758-0

[21] J.Y. Kim, On reflexive principally quasi-Baer rings, Korean J. Math. 17 (2009) 233-236.

[22] I. Krēmere, Left-star order structure of Rickart *-ring, Linear Multilinear Algebra 64 (2016) 341-352. doi:10.1080/03081087.2015.1040369

[23] F.W. Levi, Ordered groups, Proc. Indian Acad. Sci. A 16 (1942) 256-263.

[24] S. Maeda, On the lattice of projections of a Baer *-ring, J. Sci. Hiroshima Univ. Ser. A 22 (1958) 75-88.

[25] P. Šemrl, Automorphisms of $B(H)$ with respect to minus partial order, J. Math. Anal. Appl. 369 (2010) 205-213. doi:10.1016/j.jmaa.2010.02.059

[26] B.N. Waphare and Anil Khairnar, Semi-Baer modules, J. Algebra Appl. 14 (2015) 1550145 (12 pages). doi:10.1142/S0219498815501455

Received 8 February 2017 Revised 25 July 2018 Accepted 31 July 2018 